Document downloaded from:

http://hdl.handle.net/10251/64690

This paper must be cited as:

Raffaele Vitale (2015). Practical Three-Way Calibration - Book Review. Wiley. doi:10.1002/cem.2705.

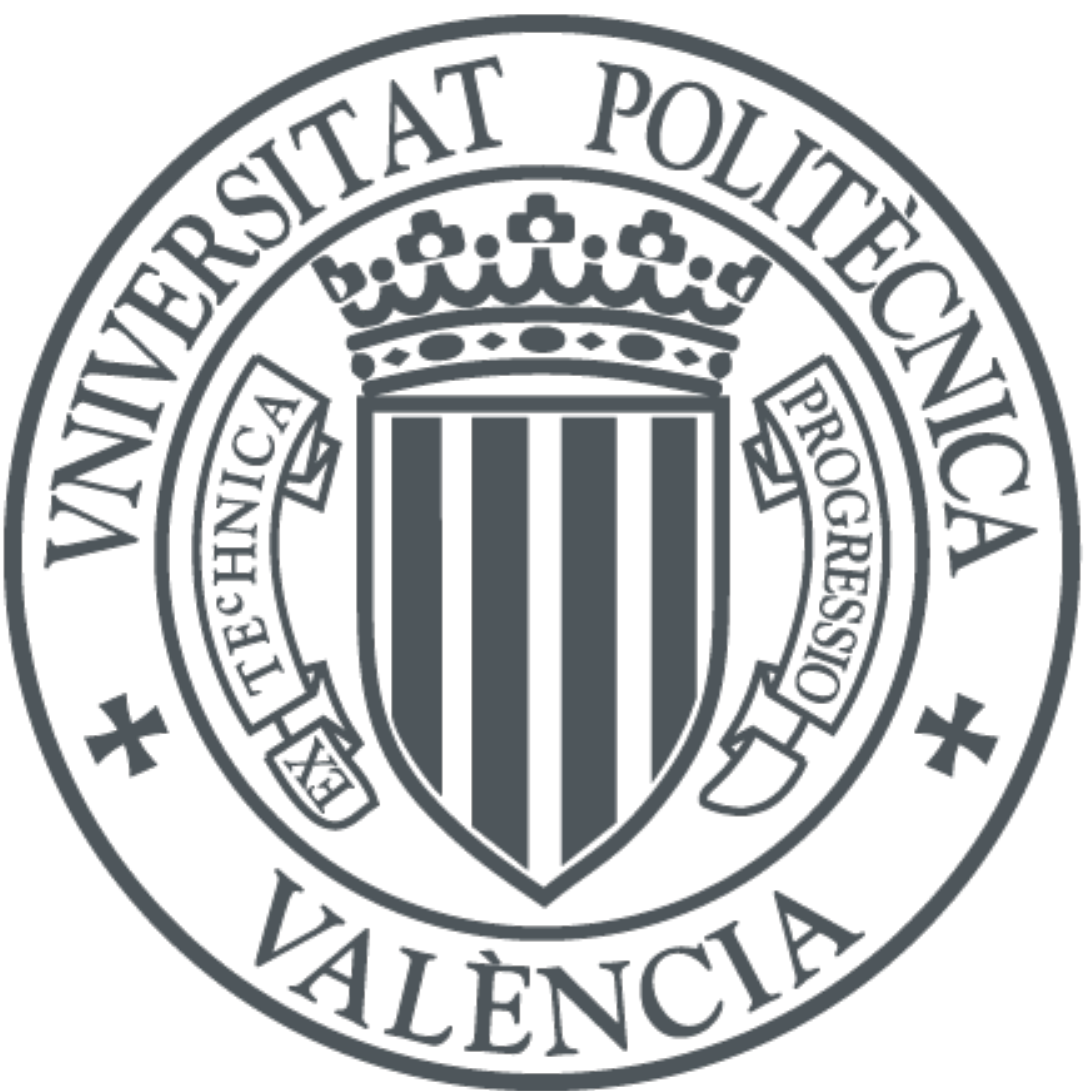

The final publication is available at

http://dx.doi.org/10.1002/cem.2705

Copyright Wiley

Additional Information 


\section{Practical Three-Way Calibration - Book Review}

Over the past twenty years, technological advancements in the development of analytical instrumentation have radically increased the quantity of processable data, which is produced over relatively small time intervals in laboratories or industrial plants. The main benefit of this continuous innovation is the ever-increasing amount of available information that characterize the systems being studied. However, in this era of the socalled data tsunami [1] how well-equipped are we to deal with vast quantities of information, and are there specific techniques in place to handle highly complex data structures? While chemometricians will undoubtedly know the answer, in the field of analytical chemistry many researchers are faced with this issue, sometimes without finding appropriate solutions.

Practical Three-Way Calibration, by Alejandro C. Olivieri and Graciela M. Escandar, is aimed at researchers and practitioners in the field of analytical chemistry, who have a basic knowledge of data analysis, and makes some headway in narrowing the gap between experimentalists and chemometrics. The book covers some practical aspects of multi-way calibration, with a special focus on new and interesting challenges that the scientific community will face in the near future. The extensive use of text, in preference to complicated formulas, and a good balance of the theoretical and practical aspects of three-way calibration, offer the reader clear and comprehensive descriptions, without compromising accuracy of the methodology and algorithms. It also enables the reader to evaluate the potential of novel multivariate statistical methods and, consider how they may be applied to their own problem-solving.

Practical Three-Way Calibration is divided into three sections. The first (Chapters 1-4) covers terms most widely-used in the field of chemical calibration clearly defined to avoid ambiguities; different types of data, generated by the modern analytical equipment, are described and classified according to their properties; and the MVC2 software (homedeveloped by the authors and used for all the reported practical examples), which is a tool for solving three-way calibration problems, is presented. The second section (Chapters 511), offers a more detailed explanation of the fundamentals of the three most common methods for building calibration models from three-way data array: Parallel Factor Analysis (PARAFAC), Multivariate Curve Resolution-Alternating Least Squares (MCRALS) and Unfolding-Partial Least Squares with Residual Bilinearization (U-PLS/RBL). Moreover, their performance is compared using several sets of data (trilinear or with different degrees of non-trilinearity), enabling novice readers to quickly identify the conditions under which a specific technique may be best applied. In Chapter 6 the definition of the classical figures of merit used in univariate calibration extends to the multi-way case, while Chapter 10 focuses on three-way calibration performed by standard addition. Of particular interest is Chapter 11 in which the properties of four-way (and briefly five-way) data are discussed, highlighting enormous potential in subject areas that, to date, have been largely unexplored. As the authors themselves state, many: 'multi-way princesses are waiting to be awakened.' The third and final section (Chapters 12-14) offers detailed descriptions of some applications of each of the three chemometric

tools. The readers are given a step-by-step guide to the processes carried out by the 
analyst, using real-life case-studies, which will encourage them to test out these approaches on their own data - a key attribute of the book. Finally, Chapter 15 contains the results of the exercises presented.

If the aim of Practical Three-Way Calibration is to provide analytical chemists with a link between the experimental tradition and contemporary complex calibration scenarios then I believe it achieves this, and much more. The main message of the book could not be clearer: 'Do it your way, but do it multi-way.' The advantage of using multi-way calibration as evidenced in the opening chapters over univariate procedures is so striking that I am convinced the reader will be less inclined to select only one wavelength of his spectra or only one retention time of his chromatograms in the future. The comparison of the different algorithms is well executed, and enables the reader to accurately select the best fit for the type of data they are working with. As a result of these two main points the reader will no doubt be inspired to use the methods described in their own case-studies, and will quickly recognise the benefits in using all the information produced by modern instrumentation.

In conclusion, Practical Three-Way Calibration represents a very useful source for anyone who wants to acquire a basic knowledge of three-way calibration, and is particularly useful for applied researchers. The text is extremely clear, and the descriptions and the explanations of the mathematical and algebraic concepts are suitable for readers who may not have a strong background in data analysis. Quoting the poet and philosopher Lucretius, the Roman rhetorician Quintilianus said in his Institutio Oratoria: 'when the topic is tough, behave veluti pueris absinthia taetra medentes cum dare conantur, prius oras pocula circum adspirant mellis dulci flavoque liquore'. Translated, as: "physicians when they seek to give a draught of bitter wormwood to a child, first smearing along the edge that rims the cup the liquid sweets of honey, golden-hued,' [2] and the authors succeeded in achieving that. For a more advanced insight, additional classical reference books and articles on this subject are cited at the end of each chapter.

\section{References:}

[1] L. Buydens, Towards tsunami-resistant chemometrics, Anal. Scien., 0813 (2013), 2430

[2] M.F. Quintilianus, Institutio Oratoria, Liber III, Chapter 1. English translation by H.E. Butler, 1920 